\title{
Feto-maternal impact of altered lipid profile in pregnancy
}

\author{
Abha Singh, Avinashi Kujur*, Parul Jain \\ Department of Obstetrics and Gynecology, Pt J. N. L. M. Medical College, Raipur, Chhattisgarh, India
}

Received: 06 December 2017

Accepted: 14 December 2017

\section{*Correspondence:}

Dr. Avinashi Kujur,

E-mail: avinashikujur@gmail.com

Copyright: $\odot$ the author(s), publisher and licensee Medip Academy. This is an open-access article distributed under the terms of the Creative Commons Attribution Non-Commercial License, which permits unrestricted non-commercial use, distribution, and reproduction in any medium, provided the original work is properly cited.

\section{ABSTRACT}

Background: This study was aimed to evaluate the association of lipid profile with development of feto-maternal complications.

Methods: This observational study was carried out in the Department of Obstetrics and Gynecology, Pt. J.N.M. Medical College Raipur during August 2015-November 2016. Total 200 study subjects were evaluated who were having normal lipid profile in $1^{\text {st }}$ trimester.

Results: Out of 200 antenatal women recruited in our study, 129 had normal lipid profile throughout pregnancy and 71 women developed dyslipidemia. $89 \%$ of those women having normal lipid profile did not develop any maternal or perinatal complication, showing a high negative predictive value $(88.72 \%)$ and high specificity of $91.47 \%$. We observed that the onset of dyslipidemia occurred in 2nd trimester and it was progressive. About $83.58 \%$ of them developed toxemia of pregnancy (GHTN, preeclampsia, eclampsia), positive predictive value of $83.58 \%$. The levels of TC (total cholesterol), TG(triglyceride), VLDL (very low-density lipoprotein) and LDL (low density lipoprotein) were significantly $(\mathrm{p}<0.0001)$ higher in hypertensive women than normotensive women. Dyslipidemic women have developed significant $(\mathrm{p}=0.00001)$ level of perinatal complications like preterm $(18.05 \%)$, IUGR $(15.28 \%)$ and IUD (13.89\%). Sensitivity- 78.9, Specificity- 88.72, Positive likelihood ratio-9.25, Negative likelihood ratio- 0.23.

Conclusions: Early pregnancy dyslipidemia was significantly associated with an increased risk of preeclampsia and eclampsia. Thus, evaluating dyslipidemia in $1^{\text {st }}$ and $2^{\text {nd }}$ trimester may help in early prediction and management of maternal as well as fetal complication.

Keywords: Eclampsia, IUGR, IUD, Lipid profile, Preeclampsia

\section{INTRODUCTION}

Hypertensive disorders complicate approximately $10 \%$ of all pregnancies worldwide, with onset of symptoms in the late second or third trimester, most commonly after the 32 nd week. ${ }^{1}$ The national incidence is reported to be 8 $10 \%{ }^{2}$ Preeclampsia is one of the major cause of maternal mortality in developed and developing countries. It is also a leading cause of perinatal morbidity and mortality and it is very strongly related to fetal growth retardation. To avoid complications, it is very important to diagnose it early, but the available tools are unable to clinch the diagnosis of preeclampsia effective in majority. Pregnancy-induced hypertension(PIH) is one of the major risk factors in present day health care practice because it not only causes maternal mortality but also impaires fetal development during pregnancy. ${ }^{3}$

Pre-eclampsia is a multi-system disorder of pregnancy, which is characterised by new onset hypertension and proteinuria that develop after 20 weeks of gestation in previously normotensive women. Pregnancy-induced hypertension $(\mathrm{PIH})$ is one of the major risk factors in present day health care practice because it not only causes 
maternal mortality but also impaires fetal development during pregnancy. ${ }^{4}$

The mechanism of causation of preeclampsia is not well understood. The available tools for its diagnosis are effective only when the disease sets in, and in many cases at this stage; it becomes difficult to prevent complications. It is necessary to diagnose this condition in advance so that the complications of mother as well as fetus may be prevented.

It is seen that severity of preeclampsia is directly related to levels of TC, TG, VLDL and LDL levels. ${ }^{5}$ In pregnancy, lipolysis of TG-rich lipoproteins is reduced because of decreased lipolytic activities of the mother. In Pre-eclampsia, the vascularization of the fetoplacental unit may be impaired, resulting in yet-undefined compensatory mechanisms that may further increase synthesis of maternal Triglyceride (TG) levels. In addition, the decreased catabolism of TG-rich lipoproteins by reduced placental uptake and the concomitant decrease of lipoprotein lipolysis results in the accumulation of TG-rich remnant lipoproteins in the maternal circulation. Remnant lipoproteins may induce platelet activation and endothelial dysfunction, thus leading to the serious complication of Pre eclampsia.

\section{METHODS}

This study was a prospective observational study which was conducted in the Department of Obstetrics and Gynaecology, Dr. B.R.A.M. Hospital, Raipur, in women attending antenatal clinic. All the women in first trimester were recruited for the study. Their lipid profile was done in each trimester. All the necessary medication was given to the patient. Any variation in BP, proteinurea and lipid profile were recorded. The fetal and maternal outcome and complications was recorded and analysed.
Serum lipid profile estimation was done by enzymatic method. LDL cholesterol (LDL-C) was calculated byFrederickson-Friedwald's formula according to which

LDL cholesterol $=$ Total cholesterol - HDL cholesterol Triglycerides (TG)/5.

VLDL cholesterol (VLDL-C) was calculated as 1/5 of Triglycerides (TG). Lipid profile concentration was measured in milligram per deciliter $(\mathrm{mg} / \mathrm{dl})$.

\section{Exclusion criteria}

Patients with diabetes mellitus, gestational diabetes, chronic hypertension (hypertension arising before 20 weeks gestation), coronary artery disease, chronic obstructive pulmonary disease (COPD).

\section{Statistical analysis}

The continuous data were summarized as mean and standard deviation while discrete (categorical) in numbers and percentage $(\%)$. The continuous variables (Lipid profile: TC, TG, HDL-C, VLDL-C, LDL-C; Blood pressure: SBP and DBP) were compared by independent student's t test. The categorical variables were compared by chi-square $(\chi 2)$ test. The $p<0.05$ was considered statistically significant with confidence interval of $95 \%$.

\section{RESULTS}

Out of 200 antenatal women recruited in our study, 129 had normal lipid profile throughout pregnancy and 71 women developed dyslipidemia. The age distribution among the two groups was not significant. Most of the women were primigravida among both dyslipidemic women and women with normal lipid profile, 59.69 and $56.34 \%$ respectively (Table 1 ).

Table 1: Demographic distribution of study participants $(\mathrm{N}=200)$.

\begin{tabular}{|c|c|c|c|c|c|c|}
\hline & & \multicolumn{2}{|c|}{ Normotensive } & \multicolumn{2}{|c|}{ Hypertensive } & \multirow[t]{2}{*}{$P$ value } \\
\hline & & $\mathrm{N}=133$ & $\%$ & $\mathrm{~N}=67$ & $\%$ & \\
\hline Age group & Mean & 24.61 & & 25.63 & & \\
\hline \multirow{4}{*}{ Parity } & 0 & 77 & 59.69 & 40 & 56.34 & 0.804 \\
\hline & 1 & 43 & 33.33 & 25 & 35.21 & \\
\hline & 2 & 06 & 4.65 & 05 & 8.45 & \\
\hline & $>2$ & 03 & 2.33 & 01 & 00 & \\
\hline \multirow{2}{*}{ Diet } & Vegetarian & 68 & 55.74 & 38 & 48.72 & \multirow{2}{*}{0.3319} \\
\hline & Non-vegetarian & 54 & 44.26 & 40 & 51.28 & \\
\hline \multirow{3}{*}{ BMI } & Underweight & 40 & 20.49 & 21 & 11.54 & 0.1002 \\
\hline & Normal & 88 & 68.03 & 33 & 62.82 & \\
\hline & Obese & 05 & 11.48 & 13 & 25.64 & 0.0093 \\
\hline \multirow{2}{*}{ BP } & SBP (mean) & 109.36 & & 110.3 & & 0.66 \\
\hline & DBP (mean) & 74.19 & & 76.32 & & 0.33 \\
\hline
\end{tabular}


Study participants when divided according to their BMI (Table 1). It was found that $59 \%$ of underweight women had normal lipid profile among which $91.7 \%$ remain normotensive while $41 \%$ women had dyslipidemia among which $72 \%$ women develop hypertension. $72 \%$ obese women had dyslipidemia and $77 \%$ among them develop GHTN. The distribution according to diet, religion and area of residency among both groups were not significant. $89 \%$ of those women having normal lipid profile did not develop any maternal or perinatal complication, showing a high negative predictive value $(88.72 \%)$ and high specificity of $91.47 \%$. We observed that the onset of dyslipidemia occurred in 2 nd trimester and it was progressive (Table 2).

Table 2: Distribution according to total cholesterol and triglyceride level.

\begin{tabular}{|c|c|c|c|c|c|c|c|}
\hline \multirow[b]{2}{*}{ Level } & & \multicolumn{6}{|c|}{ Number of patient } \\
\hline & & $\begin{array}{l}1^{\text {st }} \text { trimester } \\
\mathbf{n}=\mathbf{2 0 0}\end{array}$ & $\%$ & $\begin{array}{l}2^{\text {nd }} \text { trimester } \\
\mathbf{n}=\mathbf{2 0 0}\end{array}$ & $\%$ & $\begin{array}{l}3^{\text {rd }} \text { trimester } \\
\mathbf{n}=\mathbf{2 0 0}\end{array}$ & $\%$ \\
\hline \multirow{3}{*}{$\begin{array}{l}\text { Cholesterol } \\
\text { level }\end{array}$} & $140-220(\mathrm{~N})$ & 194 & 97 & 133 & 66.5 & 119 & 59.5 \\
\hline & $220-300$ & 06 & 03 & 69 & 34.5 & 70 & 35 \\
\hline & $>300$ & 00 & 00 & 08 & 04 & 11 & 5.5 \\
\hline \multirow{3}{*}{$\begin{array}{l}\text { Triglyceride } \\
\text { level }\end{array}$} & $30-200(\mathrm{~N})$ & 181 & 90.5 & 121 & 65.5 & 115 & 57.5 \\
\hline & $200-250$ & 16 & 08 & 68 & 34 & 71 & 35.5 \\
\hline & $>250$ & 03 & 1.5 & 11 & 5.5 & 14 & 07 \\
\hline
\end{tabular}

Table 3: Comparison of lipid profile among normotensive and hypertensive patients.

\begin{tabular}{|lllll|}
\hline & Normotensive & Hypertensive & Difference & P value \\
\hline Mean total cholesterol & 171.97 & 237 & $63.44(26.77 \%)$ & $<0.0001$ \\
\hline Mean TG & 147.80 & 237.58 & $88.02(37.05 \%)$ & $<0.0001$ \\
\hline Mean LDL & 80.04 & 154.63 & $74.59(48.24 \%)$ & $<0.0001$ \\
\hline Mean HDL & 34.74 & 35.52 & $0.78(0.02 \%)$ & 0.38 \\
\hline Mean VLDL & 29.85 & 47.53 & $17.68(37.20 \%)$ & $<0.0001$ \\
\hline
\end{tabular}

Table 4: Maternal outcome among participants.

\begin{tabular}{|llllll|} 
& Participants with normal lipid profile & Participants with dyslipidemia & P value \\
& $\mathbf{n = 1 2 9}$ & $\mathbf{\%}$ & $\mathbf{n = 7 1}$ & $\mathbf{\%}$ & \\
\hline No complication & 99 & 76.82 & 20 & 27.55 & $<0.00001$ \\
\hline GHTN & 13 & 10.14 & 10 & 14.48 & 0.0105 \\
\hline Preeclampsia & 15 & 11.59 & 33 & 46.38 & 0.00012 \\
\hline Eclampsia & 02 & 1.45 & 8 & 11.59 & 0.00034 \\
\hline
\end{tabular}

p-value $<0.00001$

Table 5: Fetal outcome among participants.

\begin{tabular}{|llllll|} 
& \multicolumn{2}{l}{ Participants with normal lipid profile } & \multicolumn{2}{l|}{ Participants with dyslipidemia } & P value \\
& $\mathbf{n = 1 2 9}$ & $\mathbf{\%}$ & $\mathbf{n = 7 1}$ & $\mathbf{\%}$ & \\
\hline No complication & 107 & 82.81 & 37 & 52.78 & $<0.00001$ \\
\hline IUGR & 12 & 09.38 & 11 & 15.28 & 0.209 \\
\hline IUD & 04 & 03.16 & 10 & 13.89 & 0.0042 \\
\hline Preterm & 06 & 04.69 & 13 & 18.05 & 0.00197 \\
\hline
\end{tabular}

p-value 0.000032

About $83.58 \%$ of dyslipidemic women developed toxemia of pregnancy (GHTN, preeclampsia, eclampsia) (Table 3), positive predictive value of $83.58 \%$.

The levels of TC (total cholesterol), TG (triglyceride), VLDL (very low-density lipoprotein) and LDL (low density lipoprotein) were significantly $(\mathrm{p}<0.0001)$ higher in hypertensive women than normotensive women. Dyslipidemic women have developed significant $(\mathrm{p}=$ 0.00001) level of perinatal complications like preterm (18.05\%), IUGR (15.28\%) and IUD (13.89\%) (Table 5). Sensitivity of this investigation is 78.9 and Specificity is $88.72 \%$. The Positive likelihood ratio-9.25and Negative likelihood ratio- 0.23 . 


\section{DISCUSSION}

In our community based study, it was found that a strong association of dyslipidemia (raised levels of TC, TG, LDL) and development of hypertensive disorders of pregnancy i.e. gestational hypertension, pre eclampsia, eclampsia as well as intra uterine growth restriction and inta uterine death of fetus.

Women in whom TG level were severely increased $(>250 \mathrm{mg} / \mathrm{dl})$ in first and then into second trimester, the chances of developing preeclampsia were found to be significant. Other studies have also supported our finding. ${ }^{4,5}$ Singh et al stated that the level of TG was found to be elevated in women with pre eclampsia compared to their normotensive counterpats. ${ }^{4}$ Vrijkotte TG et al reported that with each unit increase in triglyceride was linearly associated with an increased risk of PIH. ${ }^{5}$

In present study the onset of dyslipidemia occured in insidious manner in $2^{\text {nd }}$ trimester and was observed to be progressive which precedes culmination in complication.

There was very strong positive association of elevated levels of LDL, VLDL, TC and TG with development of hypertensive disorders. Many other studies also demonstrated this correlation. ${ }^{6-11}$ Jin WY et al, Saha D et al, Saxena S et al, Vidyabati RK, Islam NAF and Aziz R they all agree on the fact that dyslipidemia was significantly associated with pre eclampdia and eclampsia. ${ }^{6-11}$

As hypertensive disorder developed, there was development of fetal complications. The women with severe dyslipidemia developed fetal complication of severe IUGR and IUD in their late second and early third trimester with very poor outcome.

The women who developed dyslipidemia consequently developed preeclampsia $(46.38 \%)$ and eclampsia $(11.59 \%)$. These women also had poor fetal outcome as for preeclamsia had to be induced resulting in preterm deliveries.

$89 \%$ of those women having normal lipid profile did not develop any maternal or perinatal complication, showing a high negative predictive value $(88.72 \%)$.

In present study, the difference in HDL levels of hypertensive and normotensive patient were found insignificant $(p>0.05)$. While some previous studies have shown significant decrease in HDL level among hypertensive patients. $3,9,12,13$

In present study maternal dyslipidemia occurs with preeclampsia and eclampsia. There is accentuation of the normal pregnancy changes. Mean triglycerides and free fatty acid (FFA) concentration increases about 2-3 fold on average in women with preeclampsia relative to uncomplicated preganacy. Of particular significance was that dyslipidemia becomes evident during $1^{\text {st }}$ and $2^{\text {nd }}$ trimester of pregnancy far preceding the clinical manifestations of preeclampsia.

\section{CONCLUSION}

Thus, estimation of maternal lipid profile in early trimester may help in early recognition of patient at risk of developing hypertensive disorder of pregnancy before the onset of clinical symptoms and their complications for maternal and fetal benefit. The findings of this study support strong relation between dyslipidemia and development of preeclampsia and eclampsia.

\section{ACKNOWLEDGMENTS}

The authors are thankful to all the women included in the study, faculty and technical staff of department of Obstetrics and gynecology, Dr. BRAM Hospital, Pt. J. N. M. medical college, Raipur (C.G.) India, for their cooperation and support during the entire study period.

\section{Funding: No funding sources}

Conflict of interest: None declared

Ethical approval: The study was approved by the Institutional Ethics Committee

\section{REFERENCES}

1. Cunningham FG, Leveno KJ, Bloom SL, Hauth JC, Rouse DJ, Spong CV. Hypertensive disorders of pregnancy. In: Cunningham FG, et al editor. Willims Obstetrics 23 ${ }^{\text {rd }}$, New York: The McGraw Hill companies;2010:706-56.

2. Pradnya P, Mona T. Study of lipid profile in preeclampsia. Indian J Basic Appl Med Res. 2012;2(5):405-9.

3. Anjum R, Zahra N, Rehman K, Alam R, Parveen A, et al. Comparative Analysis of Serum Lipid Profile between Normotensive and Hypertensive Pakistani Pregnant Women. J Mol Genet Med. 2013;7:64.

4. Singh U, Yadav S, Mehrotra S, Natu SM, Kumari K, Yadav YS. Serum Lipid Profile in Early Pregnancy as a predictor of Preeclampsia. Int $\mathrm{J}$ Med Res Rev. 2013;1(2):56-62.

5. Vrijkotte TG, Krukziener N, Hutten BA, Vollebregt $\mathrm{KC}$, van Eijsden et al. Maternal lipid profile during early pregnancy and pregnancy complications and outcomes: the ABCD study. J Clin Endocrinol Metab. 2012;97:3917-25.

6. Jin WY, Lin SL, Hou RL, Chen XL, Han T, Jin Y et al. Associations between maternal lipid profile and pregnancy complications and perinatal outcomes: a population-based study from China. BMC Pregnancy Childbirth. 2016;16:60

7. Saha D, Roy P, Pal R, Ganguli T, Maity S, Rakshit $\mathrm{BM}$ et al. Serum lipid profile- how it alters in normotensive and hypertensive pregnant women. J Eval Med Dental Sci. 2013;2:5895-5902. 
8. Saxena S, Thimmaraju KV, Srivastava PC, Mallick AK, Das B, Sinha N et al. Role of dyslipidaemia and lipid peroxidation in pregnancy induced hypertension. J Clin Sci Res. 2015;4:205-12.

9. Vidyabati RK, Davina H, Singh NK, Singh W Gyaneshwar. Serum $\beta$ hCG and lipid profile in early second trimester as predictors of pregnancy induced hypertension J Obstet Gynecol India. 2010;60(1):4450.

10. Islam NAF, Chowdhury MAR, Kibria GM, Akhter S. Study of serum lipid profile in pre-eclampsia and eclampsia. Faridpur Med Coll J. 2010;5:56-9.

11. Aziz R, Mahboob T. Pre-eclampsia and lipid profile. Pak J Med Sci. 2007;23:751-4.
12. Mamatha S, Singh S, Sujatha MS, Mahesh M. Comparative study of lipid profile in normotensive and hypertensive pregnant women. Int J Sci Stud. 2015;3(7):222-5.

13. Gohil JT, Patel PK, Gupta P. Estimation of lipid profile in subjects of preeclampsia. J Obstet Gynecol India. 2011;61:399-403.

Cite this article as: Singh A, Kujur A, Jain P. Fetomaternal impact of altered lipid profile in pregnancy. Int J Reprod Contracept Obstet Gynecol 2018;7:1326. 